Bol. Acad. peru. leng. 48. 2009 (103-112)

\title{
ALONSO QUIJANO Y FLORENTINO ARIZA O EL AMOR COMO ACTO DE FE
}

\section{ALONSO QUIJANO ET FLORENTINO ARIZA OU L'AMOUR COMME ACTE DE FOI}

\section{ALONSO QUIJANO AND FLORENTINO ARIZA: LOVE AS AN ACT OF FAITH}

\author{
Óscar Coello \\ Universidad Nacional Mayor de San Marcos
}

\section{Resumen:}

El presente artículo indaga a la luz de una rápida confrontación intertextual el parentesco entre dos ilustres amadores de las literaturas hispánicas, procurando establecer algunas líneas doctrinarias de su azaroso ejercicio. Es también un elogio a dos grandes novelistas castellanos que tratan como nadie las aventuras terrestres del corazón humano.

Résumé:

Le présent article vise, à la lumière d'une rapide confrontation intertextuelle, à établir le rapport entre deux illustres passionnés de littérature hispanique, et à dégager plusieurs lignes doctrinaires à partir de leur exercice hasardeux. Cet article fait également l'éloge de deux grands romanciers castillans qui décrivent avec singularité les aventures mondaines du cour humain.

Abstract:

Under the light of a rapid intertextual confrontation, the kinship between two illustrious lovers of the Hispanic literatures are here investigated in 
order to establish some doctrinaire lines of their hazardous practice. It is also a praise to two big Castilians novelists who treat the terrestrial adventures of the human heart.

Palabras clave:

Cervantes; don Quijote; García Márquez; Florentino Ariza; intertextualidad.

Mots clés :

Cervantes; Don Quichotte; García Márquez; Florentino Ariza; intertextualité

Key words:

Cervantes; don Quijote; García Márquez; Florentino Ariza; intertextuality.

Fecha de recepción:

$20 / 08 / 2009$

Fecha de aceptación:

$10 / 10 / 2009$

Cuando Miguel de Cervantes publicó el Quijote tenía 58 años y ya le había ido mal en todo. Había sido un frustrado estudiante de Letras, después camarero del Nuncio Apostólico de su Santidad, mal aventurado soldado, herido, capturado; y, después, puesto en libertad gracias a un cupo de limosnas; más tarde, fue poeta de cuarta categoría, autor teatral de tercera fila, novelista de segunda, marido errante, recaudador de impuestos, preso y estafado por un limeño; finalmente, padre despreciado por la hija debido a que nunca tuvo el dinero suficiente para la dote matrimonial. Cuando tocó las estrellas con su libro bendito, sus enemigos se dieron maña, apenas un par de meses después, para tratar de envenenarle el éxtasis, y lo echaron a las mazmorras bajo la acusación de regentar un mesón cantinero con dueñas de amabilidad equívoca.

Don Miguel nunca perdió la fe en el único Dios, nunca dejó de amar al género humano, nunca dejó de entender que el único camino 
para empezarlo todo de nuevo es cuando la mente lleva un sueño dulce, es decir, cuando el corazón se juega su camino por el amor. Él entendió la literatura como el arma propicia para ganarle la partida a cualquier infortunio, descubrió a tiempo que en ella reside la satisfacción por el día imperfecto, y que la poesía se hizo para eso; que el relato, el cuento, la novela especifican la hora de recobrarnos ante cualquier zarpazo del mundo infeliz.

La literatura, pues, nos ofrece la posibilidad de hacer el mundo a nuestra imagen y semejanza; por eso el golpeado don Miguel propuso a la humanidad una manera de ser, un modo de entender las cosas, un modelo de camino cuando se trata de empezarlo todo otra vez. Y creó al personaje que ya había tenido una vida anterior, una vida con la cual no se sabía conforme porque anhelaba destinos superiores. Pero Miguel de Cervantes, por las razones que tengo dichas, acaso fue más bueno con su personaje, pues, don Alonso Quijano siquiera ya había tenido una casa, una pequeña tierra, una familia diminuta que lo quería y se preocupaba por él. Don Miguel no gozó nada de eso; y cuando murió pobre y solo, fue enterrado de caridad por las monjas trinitarias descalzas en una fosa común.

No obstante, la doctrina que plantea en su novela no es la del desatino o el odio; en el punto inicial de la locura de don Alonso está el amor como postulado. No bien presenta el personaje, apenas lo termina de vestir con su armadura de fantasía «se dio a entender que no le faltaba otra cosa sino buscar una dama de quien enamorarse; porque el caballero andante sin amores era árbol sin hojas y sin fruto, y cuerpo sin alma»1. Es decir, sin el amor nada es posible, nada se empieza o no tiene para qué ser empezado.

Es la misma razón de amor que ayer, nomás con otras palabras, escuchamos en la voz de Pablo: «Mi lucha es dura y vuelvo / con los ojos cansados / a veces, de haber visto / la tierra que no cambia / pero al

1 Miguel de Cervantes. El ingenioso hidalgo don Quijote de la Mancha, Libro I, Cap. I, p. 46.

Bol. Acad. peru. leng. 48(48), 2009 
entrar tu risa / sube al cielo buscándome / y abre para mí todas / las puertas de la vida» ${ }^{2}$. Hace cuatrocientos años, el mundo leía asombrado las razones que daba don Alonso para tener alguien a quien amar:

Decíase él: "si yo por males de mis pecados, o por mi buena suerte, me encuentro por ahí con algún gigante, como de ordinario les acontece a los caballeros andantes, y le derribo de un encuentro, o le parto por la mitad del cuerpo, o finalmente le venzo y le rindo, ¿no será bien tener a quien enviarle presentado, y que entre y se hinque de rodillas ante mi dulce señora, y diga con voz humilde y rendido: Yo, señora, soy el gigante (...) a quien venció en singular batalla el jamás como se debe alabado caballero don Quijote de la Mancha...." ${ }^{3}$

En Cervantes, pues, el amor es el que hace presumir nuestra identidad en la tierra. Puede la amada estar o no enterada del asunto, eso es irrelevante; puede o no corresponder al enamorado, eso no cuenta. Por eso, don Alonso estuvo enamorado de Aldonza Lorenzo antes de volverse loco, pero «ella jamás lo supo ni se dio cata dello» ${ }^{4}$.

Ahora, detengámonos aquí para presentar el ars amandis del americano Florentino Ariza: de él sí se sabe que comenzó amando jovencito; y que fue correspondido, aunque sea a la distancia, por carta o telegrama; es decir, poco o algo más que nada. Aun así, cuando la terrestre Fermina Daza sacó con su cuerpo las cuentas del diario vivir, solo le dijo una frase para despedirlo sin pena ni gloria: «No, por favor (...). Olvídelo» ${ }^{5}$. Y de remate, se alejó escribiéndole la milésima y última misiva de amor o desamor, en un par de líneas, porque el asunto, para ella, ya no daba para más: «Hoy al verlo, me di cuenta que lo nuestro no es más que una ilusión ${ }^{6}$. Y no importaba cuan poeta o músico era el amante, porque la mujer cuando se propone y dice no, eso significa no.

\footnotetext{
2 Pablo Neruda. Los versos del capitán, p. 18.

3 Cervantes, ídem.

4 Ibíd., p. 47.

5 Gabriel García Márquez. El amor en los tiempos del cólera, p. 144.

6 Ídem.
} 


\section{El amor como acto de fe}

Pero Fermina Daza no sabía, en su dominio de las cosas terrenales, que el reino de los poetas no corre paralelo con las leyes de este mundo. Y cuando un poeta ama de veras, eso jamás tiene fin. Por eso, el poeta dejó que se casara con otro y en un acto de fe ejemplar, deambuló por este mundo durante medio siglo en cuanto menester y devaneo se pudiera andar; y cincuenta años después, cuando el marido de Fermina se partió la espina dorsal de una caída infame, fue al entierro para verlo muerto; y, acto seguido, en el mismo crepúsculo del día de la sepultura, se presentó el poeta en el salón donde habían velado al difunto, y rigurosamente vestido de negro, llevándose el sombrero a la altura del corazón «Fermina, le dijo, he esperado esta ocasión durante más de medio siglo, para repetirle una vez más el juramento de mi fidelidad eterna y de mi amor para siempre»? Y la dejó muda como si se hubiera encontrado de pronto con un loco de la calle y, entonces, ella lo botó como el perro, pero esa noche no pudo dormir, hasta -dice el narrador- que ella «se dio cuenta de que había dormido mucho sin morir, sollozando en el sueño, y que mientras dormía sollozando pensaba más en Florentino Ariza que en el esposo muerto» ${ }^{8}$. Lo demás ya sería fácil.

Dicen los entendidos que la fe es la fuerza de soportar las dudas; de creer contra toda falta de evidencia sustancial. Cuando Cristo le muestra las llagas a Tomás para que le creyera lo que había que ver para creer, lo apartó con estas palabras: "Ahora crees porque has visto: dichosos aquellos que creen sin ver».

Esa era la fe que reclamaba Alonso Quijano. La que exigía como sustento de su amor loco. Cuando llegó al camino de las encrucijadas que se dividía en cuatro, y se topó con los seis mercaderes toledanos que iban a comprar sedas a Murcia, acompañados de siete criados, sin mediar motivo se les enfrentó e increpándolos con fuerte voz les dijo: «Todo el mundo se tenga, si todo el mundo no confiesa que no hay en el mundo todo

$\begin{array}{ll}7 & \text { Ibíd., p. } 74 . \\ 8 & \text { Ibíd., p. } 75 .\end{array}$

Bol. Acad. peru. leng. 48(48), 2009 
doncella más hermosa que la emperatriz de la Mancha, la sin par Dulcinea del Toboso» ${ }^{9}$. Con toda razón, el más juicioso de ellos le respondió:

Señor caballero, nosotros no conocemos quién sea esa buena señora que decís: mostrádnosla; que si ella fuere de tanta hermosura como significáis, de buena gana y sin apremio alguno confesaremos la verdad que por parte vuestra nos es pedida.

-Si os la mostrara -replicó don Quijote-, ¿qué hiciérades vosotros en confesar una verdad tan notoria? La importancia está en que sin verla lo habéis de creer, confesar, afirmar, jurar y defender; donde no, conmigo sois en batalla... ${ }^{10}$

Todavía le replicaron los desconcertados mercaderes, «mostradnos algún retrato de esa señora " ${ }^{11}$, pero don Alonso solo quería un acto de fe, "la importancia está en que sin verla lo habéis de creer» ${ }^{12}$, es decir, la misma doctrina que Jesús le exigía a Tomás: «Dichosos aquellos que creen sin ver».

\section{Castidad y lujuria}

El andino-caribeño Florentino Ariza, desdeñado por la juvenil Fermina, gastó los cincuenta años de soledad y contra ventura en todos los amores sin amores que pudo tener; es más, llevaba una contabilidad minuciosa de las mujeres significativas con las que se había trenzado: «... tenía unos veinticinco cuadernos con seiscientos veintidós registros de amores continuados, aparte de las incontables aventuras fugaces que no le merecieron una nota de caridad ${ }^{13}$. Hasta ya de anciano fue un viejo pederasta que usó a una niña de catorce años, la canéfora América

\footnotetext{
9 Cervantes, óp. cit., Libro I, Capítulo IV, p. 61.

10 Ídem.

11 Ídem.

12 Ídem.

13 García Márquez, ibíd., p. 210.
} 
Vicuña, que se suicidó por él cuando se dio cuenta que prefería a la senil Fermina Daza.

El viejo caballero español don Alonso Quijano, en cambio, fue casto y orgulloso de su soledad. No hacía gala sino de entretenerse en dulces pensamientos limpios de todo exceso; y si hay una escena de sexualidad desbordada en la gran historia, esta no tiene como protagonista a don Alonso, sino a un animal. Cuando don Quijote y Sancho Panza van por el bosque buscando a la pastora Marcela, se encuentran con unas yeguas que mordisqueaban la hierba junto a un pacífico arroyo y: «Sucedió, pues, que a Rocinante le vino en deseo de refocilarse con las señoras jacas; y saliendo, así como las olió, de su natural paso y costumbre, sin pedir licencia a su dueño, tomó un trotillo algo picadillo, y se fue a comunicar su necesidad con ellas. Mas ellas (...) recibiéronle con las herraduras y los dientes» ${ }^{14}$; luego, los arrieros, los dueños de las yeguas, «tantos palos le dieron, que le derribaron mal parado en el suelo» ${ }^{15}$. Debo hacer notar que aún el llamado materialista Sancho Panza se quedó admirado del proceder del caballo, pues dice: «jamás tal creí de Rocinante, que le tenía por persona casta y tan pacífica como yo» ${ }^{16}$.

\section{El cuerpo de la amada}

He dicho que Florentino Ariza fue correspondido con un canje de misivas y telegramas, por lo demás ilusorios, en el hablar de Fermina Daza. Por tanto, solo admiró su andar de venada desde lejos. En el medio siglo de espera, una vez la contempló reflejada en el espejo de un restaurante de los tiempos del cólera y le compró el espejo al dueño del restaurante pagando su precio en oro: «Cierta noche entró en el Mesón de don Sancho, un restaurante colonial de alto vuelo, y ocupó el rincón más apartado (...). De pronto vio a Fermina Daza en el gran espejo del fondo, sentada a la mesa con el marido y dos parejas más, y en un ángulo en que él podía

\footnotetext{
14 Cervantes, ibíd., Libro I, Capítulo XV, p. 118.

15 Ídem.

16 Ibíd., p. 121.
}

Bol. Acad. peru. leng. 48(48), 2009 
verla reflejada en todo su esplendor. (...) Su belleza era más radiante bajo las enormes arañas de lágrimas...» ${ }^{17}$. Es decir, nunca la tuvo de modo cierto en su condición de cuerpo bello de mujer. Cuando logró alcanzarla ya estaba implacablemente vieja y descompuesta por el calor del Caribe: «Trató de besarla en la mejilla. Pero ella lo esquivó con su voz ronca y suave. Ya no -le dijo- huelo a vieja» ${ }^{18}$. Es de un raro resplandor la escena cuando Florentino alcanza la gloria de que la anciana se despojara de sus ropas el día del juicio final:

Ella le dijo: "No mires". Él le preguntó por qué sin apartar la vista del cielo raso.

-Porque no te va a gustar- dijo ella.

Entonces él la miró, y la vio desnuda hasta la cintura (...). Tenía los hombros arrugados, los senos caídos y el costillar forrado de un pellejo pálido y frío como el de una rana. ${ }^{19}$

De Aldonza Lorenzo hay precisas referencias en el texto: «Bien la conozco - dijo Sancho-, y sé decir que tira tan bien una barra como el más forzudo zagal de todo el pueblo. Vive el Dador que es moza de chapa, hecha y derecha, y de pelo en pecho (...) qué rejo que tiene, y qué voz! Sé decir que se puso un día encima del campanario del aldea a llamar unos zagales (...) y aunque estaban de allí a más de media legua, así la oyeron como si estuvieran al pie de la torre...» ${ }^{20}$. En otro momento, hay una frase famosa que la pinta de cuerpo entero: «dicen que tuvo la mejor mano para salar puercos que otra mujer de toda la Mancha ${ }^{21}$.

Pero ni Florentino Ariza ni Alonso Quijano son amantes corporales, cuando bien aman. La estrategia del amor, como acto de fe y como única arma para enfrentar nuestros rápidos destinos cara a cara contra el tiempo ruin, es sortear los escollos del cuerpo y fabricar una entelequia que evada

\footnotetext{
$17 \quad$ García Márquez, ibíd., p. 313.

18 Ibíd., 448.

19 Ibíd., 461.

20 Cervantes, ibíd., Libro I, Capítulo XXV, p. 206-7.

21 Ibíd., Libro I, Capítulo IX, p. 84.
} 
los círculos concéntricos de la naturaleza humana. Y para eso es la poesía, para eso es la literatura: un convertir nuestros días efímeros en un trazo, en un símbolo, en el verso de una voz bien entonada. Y el tiempo ya nada puede, entonces, contra el hombre. Cuando la sensata Fermina Daza intentó poner una cadena de cordura a la voz desmemoriada e intemporal del poeta, alertándolo de su edad irreversible, él, en nombre de su alto credo se ubica y se proclama ajeno a los avatares de esta tierra. Y es que, recién lo sabemos, el amor no tiene pasado ni futuro, el amor es hoy:

Todo ha cambiado en el mundo -dijo ella.

Yo no -dijo él-. ¿Y usted?

Ella se quedó con la segunda taza de té a mitad de camino y lo increpó con unos ojos que habían sobrevivido a la inclemencia. Ya da lo mismo - dijo- acabo de cumplir setenta y dos años. ${ }^{22}$

Es decir, ella sí era sujeta del tiempo, el poeta no; pero con su entender de artista y con el arte blandido como herramienta propicia para perpetuar el amor, incluso hasta la podría salvar de conocer la humillación del sepulcro. Alonso Quijano hace cuatrocientos años nos enseñó como verdades evidentes las mismas razones: cuando Sancho termina de increparle a su amo la insignificancia antropológica y sociocultural de su amada: «pensaba bien y fielmente que la señora Dulcinea debía de ser alguna princesa de quien vuestra merced estaba enamorado $\mathrm{o}$ alguna persona tal que mereciese los ricos presentes que vuestra merced le ha enviado" ${ }^{23}$, el Quijote lo instruye, entonces, en las verdades de este azaroso ejercicio, y le explica que los poetas no aman cuerpos bellos, los crean; no aman mujeres perfectas, las inventan:

Y para concluir con todo, yo imagino que todo lo que diga [sobre ella] es así, sin que sobre ni falte nada, y píntola en mi imaginación como la deseo, así en la belleza como en la principalidad; y ni la llega Elena, ni la alcanza Lucrecia, ni otra alguna de las famosas mujeres de las edades pretéritas griega, bárbara o latina. Y diga cada uno lo que quisiere, que

22 García Márquez, ibíd., 420-21.

23 Cervantes, ibíd., Libro I, Capítulo XXV, p. 207.

Bol. Acad. peru. leng. 48(48), 2009 
si por esto fuere reprendido de los ignorantes, no seré castigado de los rigurosos. $^{24}$

Ahora, mis palabras finales: al diseñar este artículo, al tratar de dibujar algunas razones mías, declaro que he sucumbido al espejo de los textos. Una vez más, pero cada vez entendiéndolos mejor, he contemplado la verdad y la sabiduría de estos dos curtidos amadores. Ellos, en un diálogo intemporal, me han permitido cruzar información secreta, bibliografía fundamental para encarar estas mañanas contadas por las que caminamos, acosados siempre por el día muerto, por el tiempo infame, por la desazón de la verdad. Sin el amor nada somos, sin la fe para creer sin ver, nunca llegamos, sin el arte para asegurarnos la configuración del objeto amado vagamos perdidos. Don Alonso y Florentino en esto, ejemplifican lecciones de eternidad.

\section{BIBLIOGRAFÍA}

CERVANTES, Miguel de-. El ingenioso hidalgo don Quijote de la Mancha. Barcelona, Ramón Sopena, 1962.

GARCÍA MÁRQUEZ, Gabriel. El amor en los tiempos del cólera. Bogotá, Oveja Negra, 1985.

NERUDA, Pablo. Los versos del capitán. 2. a ed. Bogotá, Oveja Negra, 1985.

\section{Correspondencia:}

Oscar Coello

Docente de la Facultad de Letras y Ciencias Humanas de la Universidad Nacional Mayor de San Marcos

Correo electrónico: ocoello@oscarcoello.com

$24 \quad$ Ibíd., p. 208. 